\title{
Diagnostic electrocardiography in epidemiological studies of Chagas' disease: Multicenter evaluation of a standardized method
}

\author{
Julio O. Lázzari, ${ }^{1}$ Mauricio Pereira, ${ }^{2}$ Carlos M. F. Antunes, ${ }^{3}$ \\ Armenio Guimarães, ${ }^{4}$ Álvaro Moncayo, ${ }^{5}$ Rafael Chávez \\ Domínguez, ${ }^{6}$ Otto Hernández Pieretti, ${ }^{7}$ Vanize Macedo, ${ }^{8}$ \\ Anis Rassi, ${ }^{9}$ James Maguire, ${ }^{10}$ and Alfredo Romero ${ }^{11}$
}

\begin{abstract}
An electrocardiographic recording method with an associated reading guide, designed for epidemiological studies on Chagas' disease, was tested to assess its diagnostic reproducibility. Six cardiologists from five countries each read 100 electrocardiographic (ECG) tracings, including 30 from chronic chagasic patients, then reread them after an interval of 6 months. The readings were blind, with the tracings numbered randomly for the first reading and renumbered randomly for the second reading. The physicians, all experienced in interpreting ECGs from chagasic patients, followed printed instructions for reading the tracings. Reproducibility of the readings was evaluated using the kappa $(\mathrm{k})$ index for concordance. The results showed a high degree of interobserver concordance with respect to the diagnosis of normal vs. abnormal tracings ( $\mathrm{k}=0.66$; SE 0.02). While the interpretations of some categories of ECG abnormalities were highly reproducible, others, especially those having a low prevalence, showed lower levels of concordance. Intraobserver concordance was uniformly higher than interobserver concordance. The findings of this study justify the use by specialists of the recording of readings method proposed for epidemiological studies on Chagas' disease, but warrant caution in the interpretation of some categories of electrocardiographic alterations.
\end{abstract}

Electrocardiography is the standard method used in field studies to analyze the prevalence of heart lesions in chronic Chagas' disease (1-5). It is non- invasive, easy to apply, and of high sensitivity. However, researchers use various criteria to interpret the electrocardiograms (ECG), and this makes it

land. Requests for reprints should be sent to this author at: World Health Organization, 1211 Geneva 27, Switzerland.

Hospital Pirovano, Cardiology Division, Buenos Aires, Argentina. Correspondence should be sent to this author at: Hospital Pirovano, Coronel Díaz 2277, 1425 Buenos Aires, Argentina. E-mail: jol@efisio.fmed.uba.ar

2 University of Brasilia, Faculty of Health Sciences, Brasilia, Brazil.

3 Federal University of Minas Gerais, Institute of Biological Sciences, Minas Gerais, Belo Horizonte, MG, Brazil.

4 Federal University of Bahia, Faculty of Medicine, Salvador, BA, Brazil.

5 World Health Organization, Trypanosomiases and Leishmaniases Control, TDR, Geneva, Switzer-
Ignacio Chaves National Institute of Cardiology Mexico City, Mexico.

7 Hospital Vargas, Cardiology Section, Caracas, Venezuela.

8 University of Brasilia, Faculty of Health Sciences, Brasilia, Brazil.

9 Federal University of Goias, Faculty of Medicine, Goiania, GO, Brazil.

10 Brigham and Women's Hospital, Boston, Massachusetts, U.S.A.

11 Heart Institute, Santa Cruz, Bolivia. difficult to compare the results of different studies. In April 1988, specialists from Argentina, Bolivia, Brazil, Mexico, and Venezuela met in Buenos Aires to devise a standard method for reading ECG tracings, including recording and mounting directions, and operative definitions. ${ }^{12}$ The present study evaluated intra- and interobserver variability in ECG interpretation with the new method.

\footnotetext{
12 The meeting and the present study received financial support from the United Nations Development Project/World Bank/World Health Organization Special Program for Research and Training in Tropical Diseases (Project TDR-880342).
} 


\section{MATERIALS AND METHODS}

\section{The standardized ECG method}

The recommended procedures for recording, mounting, labeling, and reading ECGs are described in Annex 1.

\section{ECG collection and distribution}

Three centers-in Argentina, Brazil, and Venezuela-provided 120 ECG tracings recorded according to the recommended methods. Of these, 100 were selected: one-third from chronic chagasic patients with electrocardiographic alterations, onethird from patients with nonchagasic cardiopathies, and one-third normal. The tracings were numbered from 1 to 100 by means of a random numbers table. Copies of the tracings were sent to six readers from six different countries. ${ }^{13}$ All were cardiologists with expertise in the electrocardiographic diagnosis of cardiopathies, including chronic chagasic heart lesions. The readers also received information on the gender and age of each patient and forms to record the ECG interpretation (Annex 2). A manual with complete procedural instructions was also provided.

The readers recorded nine characteristics of each ECG tracing: normal vs. abnormal; rhythm; supraventricular arrhythmias; ventricular arrhythmias; atrioventricular conduction; intraventricular conduction; abnormalities of the initial portion of the QRS complex; primary alterations of ST-T waves; and miscellaneous signs.

\section{Study stages}

In stage 1 of the study, the six readers read the 100 ECGs, which were randomly numbered from 1 to 100, to provide data for evaluating interob-

\footnotetext{
13 The readers were R. Chávez, O. Hernández Pieretti,
} J. Lázzari, V. Macedo, A. Rassi, and A. Romero.

TABLE 1. Six readers' paired interobserver agreement ${ }^{\mathrm{a}}$ concerning the overall diagnosis of normal vs. abnormal ECG tracings on first and second reading

\begin{tabular}{|c|c|c|c|c|c|c|}
\hline $\begin{array}{c}\text { Observer } \\
\text { number }\end{array}$ & 1 & 2 & 3 & 4 & 5 & 6 \\
\hline \multicolumn{7}{|l|}{ First reading } \\
\hline 1 & - & $91(0.80)$ & $85(0.64)$ & $92(0.83)$ & $81(0.55)$ & $87(0.72)$ \\
\hline 2 & - & - & $86(0.67)$ & $91(0.80)$ & $82(0.58)$ & $90(0.79)$ \\
\hline 3 & - & - & - & $83(0.60)$ & $80(0.54)$ & $80(0.56)$ \\
\hline 4 & - & - & - & - & $83(0.60)$ & $87(0.72)$ \\
\hline 5 & - & - & - & - & - & $78(0.51)$ \\
\hline 6 & - & - & - & - & - & - \\
\hline \multicolumn{7}{|c|}{ Second reading } \\
\hline 1 & - & $93(0.85)$ & $82(0.57)$ & $90(0.79)$ & $89(0.77)$ & $88(0.73)$ \\
\hline 2 & - & - & $81(0.55)$ & $93(0.85)$ & $88(0.75)$ & $87(0.71)$ \\
\hline 3 & - & - & - & $82(0.59)$ & $79(0.54)$ & $84(0.61)$ \\
\hline 4 & - & - & - & - & $89(0.77)$ & $88(0.74)$ \\
\hline 5 & - & - & - & - & - & $81(0.60)$ \\
\hline 6 & - & - & - & - & - & - \\
\hline
\end{tabular}

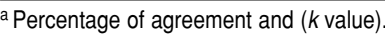

server variability. The core laboratory then collected the ECGs and all other materials from the readers. In stage 2, six months later, the readers received the same 100 ECGs, now randomly renumbered 101 to 200, and reread them using the same interpretive procedures. Comparison of these results with those of stage 1 provided data on intraobserver variability.

\section{Statistics}

The readers' ECG interpretations were analyzed using PC-AGREE, a computerized software program that measures interobserver agreement (6). The program expresses results in values of crude and specific concordance-the latter including correction for agreement due to pure chanceusing the kappa $(k)$ index (7). Potential values in this index range from -1.00 (perfect discordance) to +1.00 (perfect concordance). The degree of reader concordance was assessed using Landis and Koch's interpretive scale for $k$ values (8): $0.81-1.00$, almost perfect; $0.61-0.80$, substantial; $0.41-0.60$, moderate; $0.21-0.40$, fair; $0.00-0.20$, slight; and $<0.00$, poor. Values of the $k$ index are shown along with the standard error to evaluate statistical significance.

\section{RESULTS}

In the first reading, the paired readers' concordances with respect to the diagnosis of normal vs. abnormal tracings ranged from $78 \%$ (readers 5 and 6) to $92 \%$ (readers 1 and 4) (Table 1). The corresponding $k$ values ranged from 0.51 to 0.83 , with most falling in the range of 0.60 to 0.83 , indicating "substantial" or "almost perfect" interobserver concordance. In general, readers 3 and 5 tended to agree with other readers least often.

The overall pattern of concordance in the second readings of the ECGs, 6 months after the first, was similar to that of the first reading, but with higher values, as would be expected (Table 1). This time, the paired readers concurred on the diagnosis of normal vs. abnormal tracings in $79 \%$ (readers 3 and 5) to $93 \%$ of cases (readers 1 and 2 , readers 2 and 4), with corresponding $k$ values of 0.54 to 0.85 . Reader 5 agreed with other readers more often than the previous time.

The concordances, $k$ values, and standard errors from the six readers' first global evaluations are presented for each category in which the $k$ index could be calculated (Table 2). The crude concordance as to the diagnosis of normal vs. abnormal tracings was 
TABLE 2. Six readers' overall interobserver agreement on the assessment of the nine electrocardiographic diagnostic categories: First reading of 100 tracings

\begin{tabular}{|c|c|c|c|c|}
\hline No. & Electrocardiographic items & $\begin{array}{l}\text { Agreement } \\
(\%)\end{array}$ & $\begin{array}{l}\text { Kappa } \\
\text { index }\end{array}$ & $\begin{array}{c}\text { Standard } \\
\text { error }\end{array}$ \\
\hline $\begin{array}{l}\text { C } 1 \\
\text { C } 2\end{array}$ & $\begin{array}{l}\text { ECG, normal vs. abnormal } \\
\text { Rhythm }\end{array}$ & 85 & 0.66 & 0.02 \\
\hline \multirow{6}{*}{ C 2} & Sinus & 96 & 0.82 & 0.02 \\
\hline & Atrial ectopic & 97 & $0.04^{\mathrm{a}}$ & 0.02 \\
\hline & Junctional & 99 & $0.78^{a}$ & 0.06 \\
\hline & Idioventricular & 98 & $0.57^{a}$ & 0.06 \\
\hline & Paced & 99 & 0.84 & 0.04 \\
\hline & Atrial flutter or fibrillation & 99 & 0.96 & 0.02 \\
\hline \multirow[t]{4}{*}{ C 3} & Supraventricular arrhythmias & & & \\
\hline & None & 89 & 0.51 & 0.03 \\
\hline & Supraventricular extrasystoles & 93 & 0.56 & 0.04 \\
\hline & Other atrial arrhythmias & 94 & 0.16 & 0.03 \\
\hline \multirow[t]{7}{*}{ C 4} & Ventricular arrhythmias & & & \\
\hline & None & 96 & 0.88 & 0.02 \\
\hline & Simple ventricular extrasystoles & 92 & 0.72 & 0.02 \\
\hline & Multiform ventricular extrasystoles & 96 & 0.56 & 0.05 \\
\hline & Pairs & 97 & $0.31^{a}$ & 0.04 \\
\hline & Salvos & 100 & 1.00 & \\
\hline & Non-sustained ventricular tachycardia & 100 & 1.00 & \\
\hline \multirow[t]{4}{*}{ C 5} & Atrioventricular conduction disturbances & & & \\
\hline & None & 94 & 0.54 & 0.04 \\
\hline & Second degree AV block & 97 & 0.57 & 0.04 \\
\hline & Third degree AV block & 99 & 0.76 & 0.06 \\
\hline \multirow[t]{9}{*}{ C 6} & Ventricular conduction defects & & & \\
\hline & None & 80 & 0.60 & 0.02 \\
\hline & rR' or R in V1 & 94 & 0.85 & 0.02 \\
\hline & Left bundle branch block & 90 & 0.53 & 0.03 \\
\hline & Left anterior hemiblock & 93 & 0.69 & 0.03 \\
\hline & Left posterior hemiblock & 96 & $0.55^{\mathrm{a}}$ & 0.05 \\
\hline & Nonspecific intraventricular conduction defects & 88 & 0.31 & 0.05 \\
\hline & Intermittent occurrence of any item above & 98 & $0.64^{\mathrm{a}}$ & 0.05 \\
\hline & Other & 98 & 0.67 & 0.05 \\
\hline C 7 & Abnormal initial QRS complex & 83 & 0.40 & 0.03 \\
\hline C 8 & Primary ST-T wave changes & 69 & 0.37 & 0.02 \\
\hline \multirow{6}{*}{ C 9} & Miscellaneous & & & \\
\hline & None & 73 & 0.33 & 0.03 \\
\hline & Left ventricular hypertrophy & 92 & 0.41 & 0.04 \\
\hline & Right ventricular hypertrophy & 93 & 0.39 & 0.05 \\
\hline & $P$ wave & 82 & 0.28 & 0.03 \\
\hline & Low voltage QRS & 95 & 0.38 & 0.05 \\
\hline
\end{tabular}

a Prevalence $\leq 2 \%$.

$85 \%$, yielding a global $k$ value of 0.66 , which falls in Landis and Koch's "substantial" range. In most cases, the high value of the $k$ index combined with a very low standard error, indicating that the values are statistically significant (6). The highest concordance values were found in the diagnostic categories of cardiac rhythm and ventricular arrhythmias. The lowest values were found in the evaluation of abnormalities in the initial part of the QRS complex, primary ST-T wave changes, and of miscellaneous electrocardiographic diagnostic categories. The data from the second readings of the ECGs were similar.

It is important to note that the value of the $k$ index depends upon the prevalence of the phenomenon being observed (9). As an example of the consequences of this feature of the index, the $k$ level associated with the readers' diagnoses of atrial ectopic rhythm, an arrhythmia with a prevalence of less than $2 \%$, was only 0.04 despite $97 \%$ in- terobserver agreement. Other diagnoses whose associated $k$ values were distorted in this way included junctional and idioventricular rhythms, paired ventricular extrasystoles, left posterior hemiblock, and the intermittent occurrence of ventricular conduction defects.

Intraobserver concordance-i.e., individual readers' consistency in interpreting the same ECG tracings in the same way after an interval of 6 months-was very high except for reader 5 (Table 3). Readers 1, 2, and 4 registered very high $k$ values on the diagnosis of normal vs. abnormal tracings: $0.87,0.87$, and 0.96 , respectively, or "almost perfect concordance." Not surprisingly, intraobserver concordance was generally higher than interobserver concordance. Of all the diagnostic categories, intraobserver concordance was lowest with regard to "miscellaneous" features. This result was expected because "miscellaneous" is a residual category that includes minor ECG alterations, with low prevalence in the material analyzed.

\section{DISCUSSION}

In 1986, a WHO meeting on the feasibility of analytical epidemiological studies on Chagas' disease held in Belo Horizonte, Brazil, determined that there was a need to standardize clinical, radiologic, electrocardiographic, and laboratory protocols for diagnosing Chagas' disease in epidemiological studies (10). Experts at this meeting also recommended that coded procedures be developed for diagnostic reading of ECG tracings from chagasic patients with possible cardiac involvement. The present article reports on the inter- and intraobserver agreement characteristics of a method for interpreting electrocardiograms that was developed pursuant to these recommendations.

Expert readers in six countries displayed "almost perfect" concordance with each other in diagnosing a variety of ECGs as normal or abnormal $(k$ 


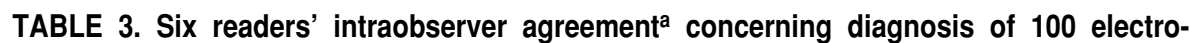
cardiographic tracings reread after a 6-month interval

\begin{tabular}{|c|c|c|c|c|c|c|c|c|c|}
\hline \multirow[b]{2}{*}{ Observer } & \multicolumn{8}{|c|}{ Electrocardiographic diagnostic categories ${ }^{b}$} & \multirow[b]{2}{*}{9} \\
\hline & 1 & 2 & 3 & 4 & 5 & 6 & 7 & 8 & \\
\hline 1 & $\begin{array}{c}94 \\
(0.87)\end{array}$ & $\begin{array}{c}97 \\
(0.87)\end{array}$ & $\begin{array}{c}87 \\
(0.61)\end{array}$ & $\begin{array}{c}88 \\
(0.56)\end{array}$ & $\begin{array}{c}93 \\
(0.51)\end{array}$ & $\begin{array}{c}87 \\
(0.78)\end{array}$ & $\begin{array}{c}80 \\
(0.28)\end{array}$ & $\begin{array}{c}88 \\
(0.66)\end{array}$ & $\begin{array}{c}59 \\
(0.33)\end{array}$ \\
\hline 2 & $\begin{array}{c}94 \\
(0.87)\end{array}$ & $\begin{array}{c}99 \\
(0.94)\end{array}$ & $\begin{array}{c}92 \\
(0.61)\end{array}$ & $\begin{array}{c}97 \\
(0.92)\end{array}$ & $\begin{array}{c}96 \\
(0.54)\end{array}$ & $\begin{array}{c}88 \\
(0.79)\end{array}$ & $\begin{array}{c}93 \\
(0.62)\end{array}$ & $\begin{array}{c}93 \\
(0.81)\end{array}$ & $\begin{array}{c}89 \\
(0.72)\end{array}$ \\
\hline 3 & $\begin{array}{c}89 \\
(0.69)\end{array}$ & $\begin{array}{c}97 \\
(0.84)\end{array}$ & $\begin{array}{c}87 \\
(0.58)\end{array}$ & $\begin{array}{c}92 \\
(0.79)\end{array}$ & $\begin{array}{c}95 \\
(0.57)\end{array}$ & $\begin{array}{c}77 \\
(0.58)\end{array}$ & $\begin{array}{c}95 \\
(0.82)\end{array}$ & $\begin{array}{c}84 \\
(0.71)\end{array}$ & $\begin{array}{c}76 \\
(0.49)\end{array}$ \\
\hline 4 & $\begin{array}{c}98 \\
(0.96)\end{array}$ & $\begin{array}{c}100 \\
(1.00)\end{array}$ & $\begin{array}{c}100 \\
(1.00)\end{array}$ & $\begin{array}{c}95 \\
(0.86)\end{array}$ & $\begin{array}{c}100 \\
(1.00)\end{array}$ & $\begin{array}{c}98 \\
(0.96)\end{array}$ & $\begin{array}{c}98 \\
(0.93)\end{array}$ & $\begin{array}{c}94 \\
(0.85)\end{array}$ & $\begin{array}{c}93 \\
(0.80)\end{array}$ \\
\hline 5 & $\begin{array}{c}78 \\
(0.52)\end{array}$ & $\begin{array}{c}88 \\
(0.56)\end{array}$ & $\begin{array}{c}83 \\
(0.34)\end{array}$ & $\begin{array}{c}92 \\
(0.79)\end{array}$ & $\begin{array}{c}60 \\
(0.41)\end{array}$ & $\begin{array}{c}84 \\
(0.28)\end{array}$ & $\begin{array}{c}87 \\
(0.56)\end{array}$ & $\begin{array}{c}68 \\
(0.36)\end{array}$ & $\begin{array}{c}64 \\
(0.17)\end{array}$ \\
\hline 6 & $\begin{array}{c}89 \\
(0.76)\end{array}$ & $\begin{array}{c}98 \\
(0.89)\end{array}$ & $\begin{array}{c}95 \\
(0.56)\end{array}$ & $\begin{array}{c}97 \\
(0.72)\end{array}$ & $\begin{array}{c}95 \\
(0.53)\end{array}$ & $\begin{array}{c}84 \\
(0.63)\end{array}$ & $\begin{array}{c}85 \\
(0.49)\end{array}$ & $\begin{array}{c}87 \\
(0.79)\end{array}$ & $\begin{array}{c}89 \\
(0.52)\end{array}$ \\
\hline
\end{tabular}

a Percentage of agreement and ( $k$ value).

b See Table 2 for individualization of the nine ECG diagnostic categories.

$=0.66 ; \mathrm{SE} 0.02)$. Interobserver concordance was "fair" to "almost perfect" with respect to the most prevalent chagasic ECG alterations: junctional rhythm $(k=0.78$; SE 0.06), idioventricular rhythm $(k=0.57$; SE 0.06), atrial flutter or fibrillation $(k=0.96$; SE 0.02$)$, supraventricular extrasystoles $(k=$ 0.56, SE 0.04), ventricular extrasystoles $(k=0.31$ to 1.00$)$, atrioventricular conduction disturbances $(k=0.51$ to $0.76)$, and ventricular conduction defects $(k=0.31$ to 0.85$)$. These results justify the use of the method for stan- dardizing data in epidemiological studies.

Concordance was lower with respect to a number of ECG diagnoses that had a lower prevalence in the ECGs analyzed. Caution is appropriate in the use of this method for these diagnoses.

Following the collection and evaluation of data, the participant investigators discussed their difficulties in reading the 100 ECGs. Their remarks were incorporated into improvements in the method, especially in regard to some of the categories and definitions with the lowest levels of concordance, which should increase its validity and reproducibility even further. Finally, it is important to note that this procedure is appropriate only for epidemiological studies, and not for clinical diagnosis of individual chagasic patients or for the diagnosis of other cardiovascular conditions. Other codes-such as the Minnesota Code $(11,12)$ or the modified Minnesota Code adapted for Chagas' disease (13)-are more suitable for the latter circumstances.

\section{REFERENCES}

1. Laranja FS, Dias E, Duarte E, Pellegrino J. Observaçoes clínicas e epidemiológicas sobre a moléstia de Chagas no oeste de Minas Gerais. O Hospital 1951;40:945-988.

2. Puigbó JJ, Nava Rhode JR, García Barrios H, Suárez JA, Yépez CG. Clinical and epidemiological study of chronic heart involvement in Chagas' disease. Bull WHO 1966;34:655-669.

3. Dias JC, Kloetzel K. The prognostic value of the electrocardiographic features of chronic Chagas' disease. Rev Inst Med Trop São Paulo 1968;10:158-162.

4. Guimarães AC. Aspectos eletrocardiográficos da cardiopatia chagásica. In: Cançado JR, Chuster M, ed. Cardiopatía chagásica. Belo Horizonte: Fundação Carlos Chagas; 1985. pp 141-147.

5. Maguire JH, Hoff R, Sherlock I, Guimarães AC, Sleigh A, Ramos NB, et al. Cardiac morbidity and mortality due to Chagas' disease: prospective electrocardiographic study of a
Brazilian community. Circulation 1987;75: 1140-1145.

6. Walter SD, Cook RJ. PC-AGREE (version 2.5): a PC program for the analysis of interobserver variation. 1988 version. Department of Clinical Epidemiology and Biostatistics, McMaster University Medical Centre, Hamilton, Ontario, Canada L8N $3 Z 5$

7. Cohen JA. Coefficient of agreement for nominal scales. Educ Psychol Meas 1960;20:37-46.

8. Landis JR, Koch GG. The measurement of observer agreement for categorical data. Biometrica 1977;33:159-174.

9. Gjorup T. The $k$ coefficient and the prevalence of a diagnosis. Methods Inf Med 1988;27: 184-186

10. United Nations Development Project/World Bank/World Health Organization Special Program for Research and Training in Tropical Diseases (TDR). Report of a Meeting on the Feasibility of Analytical Epidemiological
Studies on Chagas' Disease. Geneva: UN/ WB/WHO; 1986. (Document TDR/CHA/ $\mathrm{EPD} / \mathrm{PROTO} / 86.3$ ).

11. Blackburn H, Keyes A, Simonsen E, Rautaharju P, Punsar S. The electrocardiogram in population studies: A classification system. Circulation 1960;21:1160-1175.

12. Rose GA, Blackburn H, Gillum RF, Prineas RJ. Cardiovascular survey methods. $2^{\text {nd }}$ ed. Geneva: World Health Organization; 1982.

13. Maguire JH, Mott KE, Souza JAA, Almeida EC, Ramos NB, Guimarães AC. Electrocardiographic classification and abbreviated lead system for population-based study of Chagas' disease. Bull Pan Am Health Organ 1982;16: 47-58.

Manuscript received on 11 March 1997. Revised version accepted for publication on 1 April 1998. 


\section{ANNEX 1. The electrocardiographic recording and reading method}

This annex describes the electrocardiographic (ECG) recording and reading method designed for epidemiological studies on Chagas' disease and computer analysis, as it was used in this study. This code should not be used for the diagnosis of individual patients or for other pathologic conditions.

In the first part of the reading, some ECG measurements are recorded, such as heart rate, PR interval, and QRS interval and axis. Using these measurements, the computer will automatically diagnose certain ECG abnormalities, such as sinus tachycardia, atrioventricular $(\mathrm{AV})$ conduction disturbances, or the presence and degree of bundle branch block. Manual entry of those diagnoses is not required. For example, there is no need to code "first degree AV block," since the computer will make the diagnosis from the measurement of the AV interval, taking into account age and heart rate. Similarly, the computer will diagnose "complete" and "incomplete" bundle branch blocks using the measurement of the QRS interval. The computer will diagnose bradycardia and tachycardia from the heart rate.

For similar reasons, combinations of abnormalities of the same category are entered in isolated form when they occur in the same patient. For example, in a patient with right bundle branch block (rR') and left anterior hemiblock, the items "right bundle branch block" and "left anterior hemiblock" are entered separately. The first column of Table 2 shows the items used in this study to enter each ECG diagnosis.

The definitions of terms used in this method are strictly operational definitions and may not coincide exactly with those generally accepted in the literature.

\section{GENERAL PROCEDURES}

\section{Recording ECGs}

To obtain comparable information, all recordings are 12-lead ECGs taken on singlechannel machines. Recordings include at least three QRS complexes in each 7 to $9 \mathrm{~cm}$ long lead, and a final 30-cm lead II rhythm strip.

Electrocardiographs are calibrated such that $1 \mathrm{mV}=10 \mathrm{~mm}$. Each electrocardiogram is marked with a calibration signal. The calibration signal should have a rectangular shape. Any overshooting, overdamping, or abnormal slope should be corrected.

Each lead is identified, during or immediately following the recording, in the margin of the recording paper.

Only tracings of good quality should be accepted, avoiding artifacts, tremors, wandering baseline, and 50/60-cycle alternating current interference. The use of alternate current or muscle tremor filters should be disallowed.

\section{ECG mounting and labeling}

The 12 leads are mounted on one side of a cardboard sheet measuring $21 \times 30 \mathrm{~cm}$, as shown in Figure 1. The calibration signs along with the 12-lead ECG are mounted on one side. The $30-\mathrm{cm}$ long lead II rhythm strip is mounted on the back of the same sheet. 
FIGURE 1. Calibration signs and 12-lead ECG mounted on one side of cardboard sheet with $30-\mathrm{cm}$ long lead II rhythm strip mounted on the back

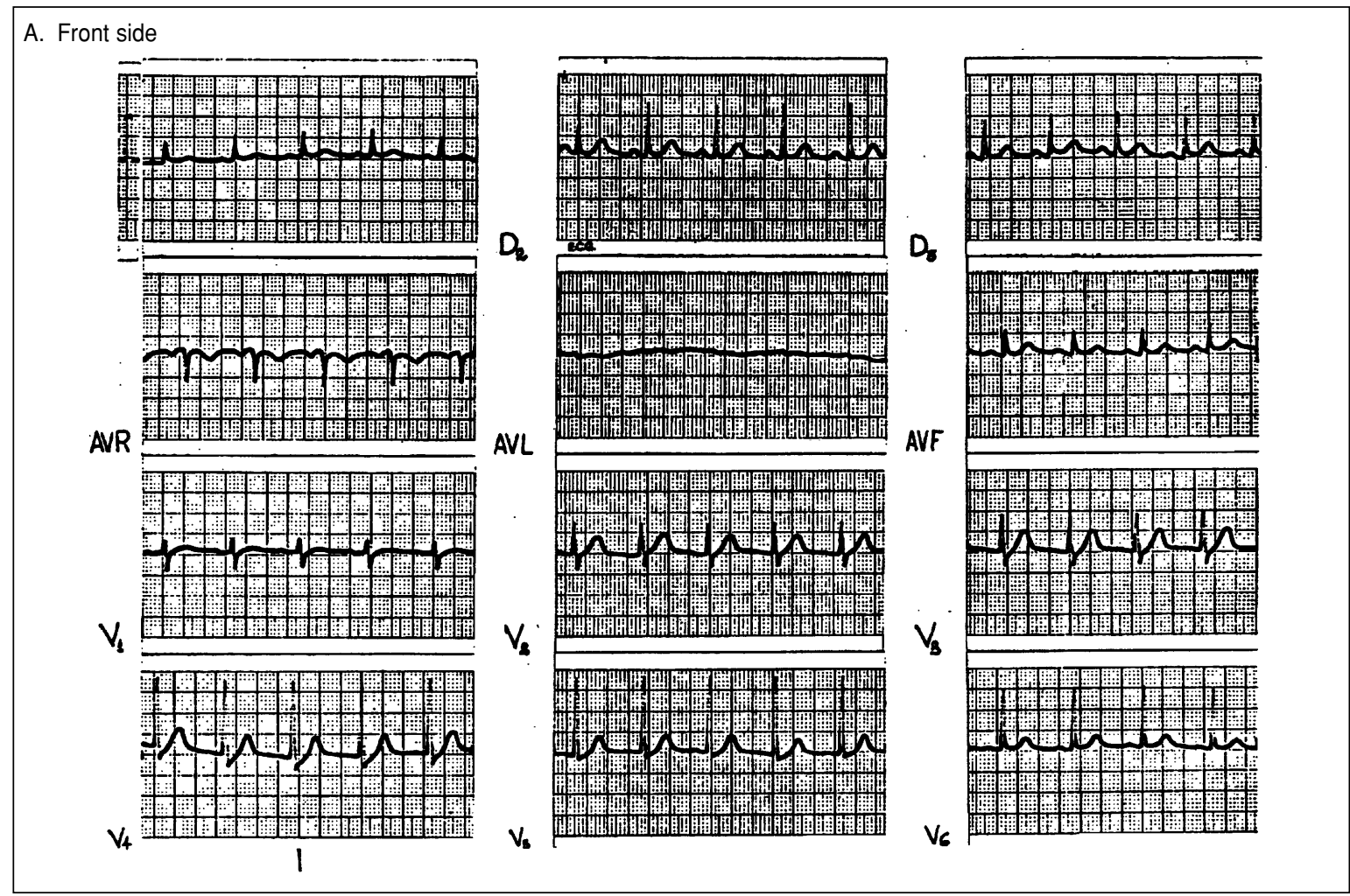

B. Back side

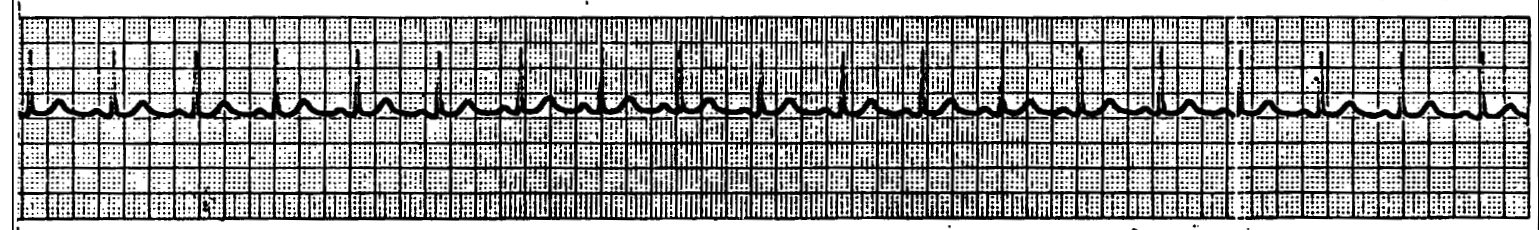




\section{ANNEX 2. Individual forms}

The interpretation of each electrocardiogram is recorded on an individual form. The form consists of three sections, on which are entered A) the individual identification data; B) five selected electrocardiographic measurements; and C) nine descriptive characteristics of the ECG pattern. At the end of this form, there is room for a short comment on ECG alterations that were not considered in the instructions.

\section{A IDENTIFICATION \\ A1 Center identification \\ A2 Subject identification \\ A3 Age \\ A4 Sex (Male/Female) \\ A5 Date $(\mathrm{dd} / \mathrm{mm} /$ yyyy)}

B ELECTROCARDIOGRAPHIC MEASUREMENTS

B1 Heart rate (bpm)

B2 PR interval ( $\mathrm{sec} / 100)$

B3 QRS duration (sec/100)

B4 QRS axis

B5 Number of ventricular extrasystoles

\section{ELECTROCARDIOGRAPHIC} PATTERN

C1 ECG (Normal/Abnormal)

C2 Rhythm

Sinus

Atrial ectopic

Supraventricular tachycardia

Atrial flutter or fibrillation

Junctional

Idioventricular

Sustained ventricular tachycardia

Paced

Unidentified

C3 Supraventricular arrhythmias

None

Supraventricular extrasystoles Supraventricular tachycardia Atrial flutter or fibrillation

Other atrial arrhythmias

C4 Ventricular arrhythmias

None

Simple ventricular extrasystoles

Multiform ventricular extrasystoles

Pairs
Salvos

$\mathrm{R} / \mathrm{T}$ phenomenon

Nonsustained VT

Sustained VT

C5 Atrioventricular conduction

disturbances

None

Type I second degree AV block

Type II second degree

AV block

2:1 AV block

High degree AV block

Third degree AV block

Atrioventricular dissociation

Ventricular pre-excitation

Noncodifiable

C6 Ventricular conduction defects

None

$\mathrm{rR}^{\prime}$ or $\mathrm{R}$ in $\mathrm{V} 1$

Left bundle branch block

Left anterior hemiblock

Left posterior hemiblock

Nonspecific ventricular conduction defect

Intermittent

Noncodifiable

C7 Abnormal initial portion of the QRS complex

None

Present

Noncodifiable

C8 Primary ST-T wave changes

None

Present

Noncodifiable

C9 Miscellaneous

None

Left ventricular hypertrophy

Right ventricular hypertrophy

$\mathrm{P}$ wave changes

Low voltage QRS

Other ECG changes. Please identify:

COMMENTS: 


\section{FILLING OUT THE FORM: INSTRUCTIONS AND TERM DEFINITIONS}

\section{Section "A": Identification}

In this section the participating center and the patient are identified, along with selected demographic data. This information is entered in the following order:
A1) Identifier for the Center
A2) Identifier for the patient
A3) The patient's age in years
A4) The patient's sex
A5) The date

\section{Section "B": Electrocardiographic measurements}

In this section five electrocardiographic measurements are entered. They are: heart rate, PR interval, QRS duration, QRS axis, and the number of ventricular extrasystoles.

B1) Heart rate in beats per minute (bpm)

The heart rate is determined by measuring the frequency of three consecutive QRS complexes of the basic ventricular rhythm in leads I and V6 and calculating the average of these two frequencies. For accuracy and reproducibility, frequency is best measured with a standard rule. If extrasystoles are frequent and three consecutive QRS complexes of the basic rhythm cannot be found, the heart rate is averaged from two different RR intervals in two different leads.

Decimal fractions should be rounded up to the nearest integer when $\geq 5$ and down to the nearest integer when $<5$. For example, frequencies of $61 \mathrm{bpm}$ in lead I and 66 bpm in lead V6 average to 63.5; this should be entered as 64. An average of 120.3, on the other hand, should be entered as 120 .

In case of paced rhythm (see definition in $\mathrm{C} 2$, below) or bigeminal rhythm, do not enter the heart rate. Instead, enter "noncodifiable." 14

\section{B2) PR interval in hundredths of a second}

The PR interval should be measured along the upper edge of the inscription line, from the beginning of the $\mathrm{P}$ wave to the beginning of the QRS complex, whether the complex starts with a $Q$ wave or an $R$ wave. The PR interval should be measured during a period of regular sinus rhythm. The longest PR interval found in either the standard limb leads or V1 to V6 should be recorded. If this interval cannot be measured, enter "noncodifiable."

Do not measure PR interval in the complex following a ventricular extrasystole, nor in cases of paced rhythm or type I second degree AV block (Wenckebach phenomenon). In these cases, enter "noncodifiable." PR interval "noncodifiable" should be entered in cases of atrial fibrillation, ventricular tachycardia, and junctional rhythm.

\section{B3) QRS duration in hundredths of a second}

Measure the QRS duration from the beginning to the end of the QRS complex in those leads where its initial and last portions are well defined. Enter onto the form the longest QRS duration measured in the standard limb leads or V1 to V6. Measure QRS duration on the basal or predominant supraventricular rhythm.

Do not measure QRS duration when paced rhythm is present (see definition below, section C2). In this case enter "noncodifiable."

Also enter "noncodifiable" in cases of ventricular tachycardia or idioventricular rhythm.

\footnotetext{
14 Italicized items contain modifications to the method introduced following the evaluation for observer variability,
} based on the experiences of the six readers. 


\section{B4) QRS axis}

The QRS axis should be determined with an approximation of $10^{\circ}$. In the presence of right bundle branch block (here referred to as $\mathrm{rR}^{\prime}$, or R in V1), use only the first 0.04 to 0.06 second of the QRS complex to determine the axis. Note the axis as "noncodifiable" in cases of biphasic QRS complexes in leads I, II, and III that do not allow axis determination by the usual methods.

Do not measure QRS axis in the presence of idioventricular rhythm, paced rhythm, sustained ventricular tachycardia, or ventricular pre-excitation. Nor should it be measured in cases of atrial flutter or fibrillation with high ventricular response where the amplitude of the QRS complex changes from beat to beat. In all these cases, note "noncodifiable."

\section{B5) Number of ventricular extrasystoles}

Ventricular extrasystoles should be counted only in the 30-cm lead II rhythm strip. Enter the number present.

If ventricular extrasystoles occur in the 12-lead ECG but not in the 30-cm rhythm strip, enter " 0 ventricular extrasystoles."

If sustained ventricular tachycardia as defined below coincides with a 30-cm lead II rhythm strip that lacks ventricular extrasystoles or tachycardia, enter "0 ventricular extrasystoles."

If the 30-cm lead II rhythm strip records a nonsustained ventricular tachycardia of any duration, each complex of the tachycardia should be counted as a ventricular extrasystole.

Example:

Ventricular extrasystoles $=6$ : enter 06 .

Ventricular extrasystoles present in the 12-lead ECG but not in the lead II 30-cm rhythm strip: enter " 0 ventricular extrasystoles."

Ventricular tachycardia with 36 beats recorded in the lead II 30-cm rhythm strip: enter 36.

Ventricular extrasystoles absent in the lead II 30-cm rhythm strip: enter "0 ventricular extrasystoles."

\section{Section " $C$ ": Descriptive characteristics of the ECG}

In this section, nine descriptive characteristics of the ECG pattern are recorded. They are: C1) normal vs. abnormal ECG; C2) rhythm; C3) supraventricular arrhythmias; C4) ventricular arrhythmias; C5) atrioventricular conduction disturbances; C6) ventricular conduction defects; C7) abnormal initial QRS complex; C8) primary ST-T wave changes; and C9) miscellaneous.

This section includes a definition of the ECG alterations. It is stressed that the definitions are operative only for epidemiological studies using this method and may not correspond with other definitions in the literature.

\section{C1) ECG}

Normal = without codifiable alterations. In absence of any alteration of the ECG (e.g., item C2 is a "sinus" and items C3 to C9 are "none").

Abnormal = with codifiable alterations. If item C2 is different from "sinus" and items C3 to C9 are different from "none".

\section{C2) Rhythm}

Sinus: Regular inscription of normal P waves. Sinus rhythm includes normal sinus rhythm (50-99 bpm), sinus tachycardia ( $\geq 100 \mathrm{bpm})$, and sinus bradycardia $(<50$ bpm).

Atrial ectopy, wandering pacemaker or multiform atrial rhythm: An atrial ectopic rhythm is an atrial rhythm different from sinus rhythm that has a frequency $<100 \mathrm{bpm}$. A wandering pacemaker is a slow sinus rhythm that leads to frequent atrial ectopic escape beats with the possibility of atrial fusion complexes. A multiform atrial 
rhythm is an atrial rhythm with 3 or more P waves of different shapes in the same lead and a frequency of less than $100 \mathrm{bpm}$.

Supraventricular tachycardia: Atrial ectopic or AV junctional rhythm at a frequency of 100 bpm or higher.

Atrial flutter or fibrillation: Atrial flutter is rapid and regular atrial activity with absence of an isoelectric line that results in an atrial rate in the range of 200 to $400 \mathrm{bpm}$. Atrial fibrillation is rapid, irregular, and disorganized atrial activity that distorts the baseline and results in an atrial rate in the range of 400-600 waves per minute. $\mathrm{AV}$ conduction is irregular and results in a completely irregular occurrence of the QRS complexes, except in the presence of third degree AV block or junctional or idioventricular rhythms.

Junctional: Regular or slightly irregular rhythm with a rate $<100 \mathrm{bpm}$, with QRS complexes normal or slightly abnormal in shape, in the absence of previous intraventricular conduction disturbances. $P$ waves can precede, coincide with, or follow the QRS complexes.

Idioventricular: Regular or slightly irregular ectopic ventricular discharge at a rate slower than $100 \mathrm{bpm}$

Sustained ventricular tachycardia: Regular ectopic ventricular discharge at a rate $\geq 100 \mathrm{bpm}$, present throughout the 12-lead electrocardiogram.

Paced: Rhythm originating in the atria or the ventricle as a consequence of the activity of an artificial pacemaker. If one or even more captures of an atrial or ventricular pacemaker in the 12-lead electrocardiogram or in the 30-cm lead II rhythm strip is observed, then the rhythm should be considered "paced." If a malfunctioning pacemaker is observed with no captures, then the diagnosis corresponding to the prevailing rhythm should be entered.

Unidentified: Any rhythm that cannot be identified with accuracy.

Note: Only one diagnosis should be entered in this item. In cases of complete AV block and sinus rhythm, atrial ectopy, wandering pacemaker or multiform atrial ectopic rhythm, supraventricular tachycardia or atrial flutter or fibrillation, enter one of the other options: junctional, idioventricular, sustained ventricular tachycardia, paced or unidentified rhythm.

\section{C3) Supraventricular arrhythmias}

Supraventricular arrhythmias should be sought only in the 12-lead electrocardiogram, not in the 30-cm lead II rhythm strip.

None: Absence of any supraventricular arrhythmia.

Supraventricular extrasystoles: Impulses that arise in the atria or the AV junction and occur prematurely in relation to the prevailing rhythm.

Supraventricular tachycardia: Rapid succession of three or more consecutive ectopic atrial or AV junctional impulses with frequency $\geq 100 \mathrm{bpm}$.

Atrial flutter or fibrillation: Atrial flutter is rapid and regular atrial activity with absence of an isoelectric line that results in an atrial rate in the range of 200 to $400 \mathrm{bpm}$. Atrial fibrillation is rapid, irregular, and disorganized atrial activity that distorts the baseline and results in an atrial rate in the range of 400 to 600 waves per minute. AV conduction is irregular and results in a completely irregular occurrence of the ORS complexes, except in the presence of third degree $A V$ block or junctional or idioventricular rhythms.

Other atrial arrhythmias: Sino-atrial (SA) block comprises delay or complete block of the sinus impulse at the sino-atrial junction. In Type I second degree SA block, there is a progressive shortening of the PP intervals followed by a pause. The pause is longer than any single PP interval but shorter than any two PP intervals. In Type II second degree SA block, there is an intermittent absence of a P wave associated with a constant preceding PP interval. Sinus arrest is the temporary or permanent absence of $\mathrm{P}$ waves. The pauses caused by the temporary absence of $\mathrm{P}$ waves are not multiples of the previous PP intervals.

All the coded supraventricular arrhythmias present in the 12-lead electrocardiogram should be recorded. 


\section{C4) Ventricular arrhythmias}

Ventricular arrhythmias should be analyzed only in the 12-lead electrocardiogram and not in the $30-\mathrm{cm}$ lead II rhythm strip.

None: Absence of ventricular extrasystoles in the 12-lead electrocardiogram.

Simple ventricular extrasystoles: Impulses that arise in the ventricle and occur prematurely in relation to the prevailing rhythm.

Multiform ventricular extrasystoles: Two or more ventricular extrasystoles of two or more different shapes.

Pairs: Two successive ventricular extrasystoles of the same or different shape.

Salvos: Three successive ventricular extrasystoles of the same or different shape occurring at $\geq 100 \mathrm{bpm}$.

$\mathrm{R} / \mathrm{T}$ phenomenon: Ventricular extrasystole interrupting the $\mathrm{T}$ wave of the previous beat belonging to the sinus or prevailing rhythm.

Nonsustained ventricular tachycardia: Four or more consecutive ventricular impulses with the same or different shape occurring at a frequency $\geq 100 \mathrm{bpm}$ not covering the entire 12-lead electrocardiogram.

Sustained ventricular tachycardia: Consecutive ventricular impulses with the same or different shape occurring at a frequency $\geq 100 \mathrm{bpm}$ covering the entire 12-lead electrocardiogram.

All the coded ventricular arrhythmias present in the 12-lead electrocardiogram should be recorded.

\section{C5) Atrioventricular conduction disturbances}

Any of the AV conduction disturbances listed here should be recorded if present. First degree AV block is not listed, since this diagnosis is obtained from measurements recorded in Sections A and B (the heart rate, patient's age, and PR interval). In case of first degree AV block, code "none."

In cases of rhythm coded "paced" (see definition in C2), idioventricular rhythm, or sustained ventricular tachycardia, enter "noncodifiable."

None: Normal AV conduction or first degree AV block.

Type I second degree AV block (Wenckebach phenomenon): The PR interval increases progressively in consecutive conducted impulses, until an atrial impulse is blocked and the $\mathrm{P}$ wave is not followed by a QRS complex. The consequent pause is longer than any previous RR interval and shorter than any two of them.

Type II second degree AV block (Mobitz type II AV block): The blocked P wave is preceded by two or more consecutive impulses with fixed PR intervals.

2:1 AV block: One of every two P waves is conducted to the ventricles.

High degree AV block: Blockade of two or more consecutive P waves not belonging to a Wenckebach sequence.

Third degree AV block: Complete interruption of AV conduction with independent activation of the atria and the ventricles.

Atrioventricular dissociation: One pacemaker activates the atria while another pacemaker, located in the AV junction or the ventricles, concomitantly but independently activates the ventricles. The atrial rate is usually slower than the ventricular rate. AV dissociation is always secondary to other rhythm disturbances and should not be mistaken for third degree AV block.

Ventricular pre-excitation: Short (classical WPW syndrome) or normal (Mahaim form) PR interval, wide QRS complex, delta wave, and secondary ST-T wave changes.

Noncodifiable: Enter this diagnosis in the following cases: "paced" rhythm or idioventricular rhythm or sustained ventricular tachycardia.

\section{C6) Ventricular conduction defects}

Ventricular conduction defects are diagnosed only in the presence of supraventricular rhythm and the absence of ventricular pre-excitation.

None: Normal intraventricular conduction. 
$\mathrm{rR}^{\prime}$ or $\mathrm{R}$ in V1: This is an operative and descriptive definition whose significance will be estimated according to the QRS duration recorded in Section B as a normal variant, incomplete right bundle branch block, or complete right bundle branch block. It is understood that there are some right bundle branch block patterns of different degrees that do not appear as $\mathrm{rR}^{\prime}$ or R in V1. In those cases, an abnormal QRS duration recorded in Section B will point to an intraventricular conduction defect.

Left bundle branch block: Enter this code in cases of complete or incomplete left bundle branch block. Complete left bundle branch block consists of QRS duration $\geq 0.12 \mathrm{sec}$; slurred $\mathrm{R}$ wave in leads I, aVL, V5, and V6, absence of q wave in leads I, V5, and V6; small or absent $r$ wave in lead SV1 and V2 and secondary ST-T wave changes. Incomplete left bundle branch block consists of QRS duration $<0.12 \mathrm{sec}$; absence of $\mathrm{q}$ wave in leads I, V5, and V6; and small or absent $\mathrm{r}$ wave in leads SV1 and V2.

Left anterior hemiblock: Frontal plane AQRS located between $-45^{\circ}$ and $-85^{\circ}$, with qR complex in leads I and aVL, rS complex in II, III, and aVF. The lead III S wave should be deeper than the lead II S wave when not associated with right bundle branch block.

Left posterior hemiblock: Frontal plane AQRS located between $+90^{\circ}$ and $+120^{\circ}$, with rS complex in leads I and aVL, qR complex in leads II, III, and aVF, and absence of right ventricular hypertrophy or a vertical heart.

Nonspecific intraventricular conduction defect: In the absence of ventricular preexcitation, any QRS complex with duration $\geq 0.10$ second that is not attributable to a block in a bundle branch or its divisions according to the above definitions.

Intermittent: Intermittent occurrence of right or left bundle branch block, left anterior or posterior hemiblock, or nonspecific intraventricular conduction defect.

Noncodifiable: Idioventricular rhythm, paced rhythm, sustained ventricular tachycardia, or ventricular pre-excitation.

\section{C7) Abnormal initial portion of the QRS complex}

Abnormalities of the initial portion of the QRS complex should be recorded only in the basic supraventricular rhythm.

Abnormalities of the initial portion of the QRS complex are not considered in cases of: paced rhythm; idioventricular rhythm; sustained ventricular tachycardia; ventricular pre-excitation; supraventricular tachycardia with aberrant intraventricular conduction of the left bundle branch block type when it is sustained throughout the 12lead electrocardiogram and the abnormality is present in V1 to V3, and in cases of left bundle branch block if the abnormality is present in V1 to V3. In all these cases, record "noncodifiable."

Care should be taken to distinguish abnormal initial QRS complex in leads SV1 to V3 due to necrosis, incomplete left bundle branch block, or a change of the heart position, such as clockwise rotation along the longitudinal axis.

None: Absence of any abnormality in the initial portion of the QRS complex.

Present: Q waves $\leq 0.04 \mathrm{sec}$ in duration, and/or Q waves in lead SV1 and V2 in the absence of left bundle branch block or ventricular pre-excitation, and/or $\mathrm{Q}$ waves with voltage $\geq 25 \%$ of that of the following $R$ wave, and/or $R$ waves decreasing in voltage or having a poor progression in precordial leads in the presence of a normal progression of $S$ waves.

Non-codifiable: Enter this diagnosis for: paced or idioventricular rhythm; ventricular pre-excitation, sustained ventricular tachycardia, left bundle branch block with abnormalities present in V1 to V3, or supraventricular tachycardia with aberrant intraventricular conduction of the left bundle branch block type with abnormalities present in leads SV1 to V3.

\section{C8) Primary ST-T wave changes}

These characteristics are considered present only in the absence of ECG alterations leading to secondary changes of ventricular repolarization. Do not record complexes 
that follow episodes of atrial flutter or fibrillation, supraventricular tachycardia, any ventricular arrhythmia, or any intermittent intraventricular conduction defect. Early repolarization is considered a normal variant.

None: Absence of any primary or secondary change in the ventricular repolarization.

Present: Presence of one or more of the following alterations: flat, biphasic, or inverted T waves; symmetric T waves; rectilinear ST segment; ST elevated $\geq 0.2 \mathrm{mV}$; ST depressed $\geq 0.1 \mathrm{mV}$; inverted $\mathrm{U}$ wave.

Noncodifiable: Enter this code in the following cases: supraventricular tachycardia with aberration, when it is sustained throughout the 12-lead ECG; atrial flutter or fibrillation; junctional rhythm with aberrant conduction; idioventricular rhythm; ventricular pre-excitation; sustained ventricular tachycardia; paced rhythm; left, right, or combined ventricular hypertrophy; nonspecific intraventricular conduction defect.

\section{C9) Miscellaneous}

This item comprises relatively less specific electrocardiographic changes that have not been considered above.

None: Absence of any alteration considered below.

Left ventricular hypertrophy: Presence of one or more of the following alterations: $\mathrm{SV} 1+\mathrm{RV} 5-\mathrm{V} 6 \geq 3.5 \mathrm{mV}$ in a patient aged $\geq 35$ years; $\mathrm{R} 1+\mathrm{S} \mathrm{III} \geq 2.5 \mathrm{mV}$ in a patient aged $\geq 35$ years; $\mathrm{R}$ wave in lead $\mathrm{aVL}>1.1 \mathrm{mV}$; $\mathrm{R}$ wave in leads $\mathrm{V} 5$ or $\mathrm{V} 6>2.6 \mathrm{mV}$. Further support is given if the alteration is associated with one or more of the following: rectilinear or depressed ST segment in leads I, aVL, V5, and V6; flat or asymmetrical inverted $\mathrm{T}$ wave in leads $\mathrm{I}, \mathrm{aVL}, \mathrm{V} 5$, and $\mathrm{V} 6$; negative $\mathrm{U}$ wave in leads I, aVL, V5, and V6; leftward deviation of the AQRS in the frontal plane with counter-clockwise rotation (q1-S3); P waves suggesting left atrial enlargement.

Right ventricular hypertrophy: Presence of one or more of the following alterations: rightward deviation of the frontal plane; AQRS $\left(\geq 110^{\circ}\right)$ with clockwise rotation (S1-q3); R/S ratio in lead V1 >1; R wave in lead V1 $\geq 0.7 \mathrm{mV}$ in absence of posterior myocardial infarction, positional changes, right bundle branch block, or ventricular pre-excitation; $\mathrm{S}$ wave in lead $\mathrm{V} 1<0.2 \mathrm{mV}$ and deep $\mathrm{S}$ wave in lead V2; $\mathrm{S}$ wave in lead V3 deeper than $\mathrm{S}$ wave in lead V2; qR pattern in lead V1 with $\mathrm{R}^{\prime}$ $\geq 1 \mathrm{mV}$; RV1 + SV5 or SV6 $\geq 1.5 \mathrm{mV}$; $+\mathrm{SR}^{\prime}$ in lead V1 with $\mathrm{R}^{\prime} \geq 1 \mathrm{mV}$. Further support is given by the association of one or more of the following alterations: depressed ST segment with inverted T waves in the right precordial leads; negative $\mathrm{U}$ wave in right precordial leads; $\mathrm{P}$ waves suggesting right atrial enlargement.

$P$ wave changes.

Low voltage QRS: The sum of the positive and negative waves does not exceed $0.5 \mathrm{mV}$ in any of leads I, II, or III and $1.0 \mathrm{mV}$ in any precordial lead.

Other ECG changes: ECG alterations not specified above should be entered here, with brief descriptions of the changes observed. 
RESUMEN Con objeto de evaluar su reproducibilidad diagnóstica, se ensayó un método de registrar resultados electrocardiográficos con una guía para su lectura, diseñado para estudios epidemiológicos de la enfermedad de Chagas. Seis cardiólogos de cinco

Diagnóstico electrocardiográfico en estudios epidemiológicos de la enfermedad de Chagas: evaluación multicéntrica de un método estandarizado países interpretaron, cada uno independientemente, los trazos de 100 electrocardiogramas (ECG), incluidos 30 de pacientes chagásicos crónicos, que los mismos cardiólogos releyeron después de un intervalo de 6 meses. Las lecturas se hicieron a ciegas, con los trazos enumerados al azar para la primera interpretación y reenumerados de la misma forma para la segunda lectura. Todos los cardiólogos que participaron en el estudio tenían experiencia en la interpretación de ECG de pacientes chagásicos y siguieron instrucciones impresas para la lectura. La reproducibilidad de las interpretaciones se evaluó por medio del índice kappa $(k)$ de concordancia. Los resultados indicaron un alto grado de concordancia entre observadores con respecto al diagnóstico de gráfico normal frente a anormal $(k=0,66$ : EE 0,02$)$. En tanto que las interpretaciones de algunas categorías de anormalidades ECG fueron reproducibles en alto grado, otras, especialmente las de baja prevalencia, tuvieron grados menores de concordancia. La concordancia intraobservador fue en todos casos mayor que la interobservador. Los resultados de este estudio justifican el uso por especialistas del método de lectura propuesto para estudios epidemiológicos sobre la enfermedad de Chagas, pero se recomienda interpretar con precaución ciertas categorías de alteraciones electrocardiográficas. 